\title{
Pensamento Computacional Desplugado e Transtornos do Aprendizado: Experiência na Educação Básica
}

\author{
Emanuelle M. P. Simas ${ }^{1}$ e Claudia L. R. da Motta ${ }^{2}$ \\ ${ }^{1}$ Faculdade de Fonoaudiologia- Universidade Federal do Rio de Janeiro(UFRJ) \\ ${ }^{2}$ Programa de Pós-Graduação em Informática e Instituto Tércio Pacitti (NCE/UFRJ) \\ Rio de Janeiro - RJ - Brasil \\ ellesimas@gmail.com, claudiam@nce.ufrj.br
}

\begin{abstract}
This article presents experience accounts of unplugged computational thinking(UCT) in extracurricular classes ministred by project 'SupyGirls: Empoderamento feminino nas Tecnologias' for students with learning disabilities of a public school at a conflicted region in Rio de Janeiro, from august 2018 to july 2019.
\end{abstract}

Resumo. Este artigo apresenta relato de experiência da aplicação do pensamento computacional desplugado (PCD) em aulas extracurriculares ministradas pelo projeto 'SupyGirls: Empoderamento feminino nas Tecnologias' para estudantes com transtornos de aprendizagem em escola pública situada em região conflagrada do Rio de Janeiro, no período de agosto de 2018 a julho de 2019.

\section{Introdução}

O analfabetismo funcional, a defasagem no aprendizado e a evasão são problemas relevantes da educação Brasileira. Análises quantitativas apontam desempenho díspar na comparação entre os anos iniciais e finais do ensino fundamental brasileiro [INEP, 2018]. Neste mesmo censo é possível ratificar a assimetria entre a educação pública e privada; neste último, a positiva linearidade nos resultados apontam superior aproveitamento, enquanto alunos da rede pública respondem em declínio latente.

Frente a este quadro e entendendo que a computação e a tecnologia não estão apenas atreladas à manipulação de variáveis numéricas e uso de computadores, o presente artigo busca relatar a experiência onde o PC [Wing, 2006] foi tangenciado às ementas do currículo de linguagens e ciências do ciclo básico. A abordagem tem por escopo a competências linguísticas e lógico-matemáticas e o aprimoramento destas através do pensamento computacional, justificando-se pois as estruturas gerativas de aprendizado e linguagem perpassam, na ambiência meta, as arquiteturas matemáticas.

Este trabalho está dividido da seguinte maneira: Seção 2 apresentamos trabalhos correlatos e referenciais teóricos. Na seção 3, a caracterização do projeto, a metodologia, materiais utilizados, principais atividades, metas e objetivos. Os resultados parciais e análises são descritos na Seção 4. As considerações finais sobre a experiência na Seção 5.

\section{Trabalhos Relacionados}

Quanto à inovação metodológica, ludicidade e pensamento computacional desplugado para reforço pedagógico da educação básica, [Guarda et al. 2018] propõe a elaboração de três atividades lúdicas que trabalham habilidades como montagem de sequências 
VIII Congresso Brasileiro de Informática na Educação (CBIE 2019)

Anais do XXV Workshop de Informática na Escola (WIE 2019)

lógicas, lógica de programação, criptografia a fim de melhorar o rendimento dos escolares em sala de aula no contexto das ciências exatas.

[Rodrigues, 2018] trouxe em sua dissertação a utilização dos chamados games inteligentes quando vinculados à grade de ciências biológicas do Ensino Fundamental II. Neste experimento, os alunos são orientados a associar os conteúdos à taxonomia de Bloom estruturando-a em narrativas coesas que originaram games point and click game.

\subsection{Referenciais Teóricos}

A metodologia baseia-se em modelos neurocientíficos, cognitivistas e sóciointeracionistas.

\subsubsection{Povoamento do imaginário}

A cultura é um grande mediador no desenvolvimento da linguagem. A partir do armazenamento e gradual categorização das informações nela contida que o indivíduo, assimilando arquétipos sociais e signos linguísticos, constrói imagens mentais do mundo externo, internaliza estruturas generativas e abstrações formais [Vygotsky, 1993].

\subsubsection{Funções Executivas, Pensamento Computacional e PCD}

Função executiva é um conceito neuropsicológico aplicado aos processos cognitivos responsáveis pelo planejamento de atividades, envolvendo manutenção da atenção, memória de curto prazo, controle do tempo, flexibilidade cognitiva e inibição de impulsos. Estudos apontam [Ruedaa et al, 2013] que tais funções são imprescindíveis para a regulação emocional. Déficits no desenvolvimento de tais funções podem ser reflexo do comportamento do indivíduo que se apresenta desmotivado, hiperativo, desatento ou até mesmo irritadiço.

O pensamento computacional instância métodos e modelos que auxiliam na resolução de desafios de modo inovador e dinâmico refletindo diretamente na capacidade analítica do indivíduo [Wing, 2006]. Como eixos do PC ressalta-se a abstração, automação e a análise [SBC, 2018]. O pensamento computacional desplugado define-se como a manifestação sem a utilização de máquinas computacionais ou dispositivo eletrônico.

\subsubsection{Fio Condutor Pedagógico Metacognitivo e Metacognição}

O Fio Condutor Pedagógico Metacognitivo [Rodrigues, 2018] se trata de um máquina de estados não determinística de desenvolvimento cognitivo, onde o aluno é levado através de suas fases a trabalhar a composição e decomposição de problemas, abstração e resolução de problemas, provocando assim o desenvolvimento da metacognição.

A metacognição é definida pela psicologia cognitiva como a competência de autoregulação e otimização do processos relacionados ao pensamento, à cognição humana. Seminério et al. [1998] e Shimamura [1992] apontam a habilidade de "pensar sobre o próprio pensamento" e "saber como se sabe’. Essa consciência e o domínio dos próprios processos cognitivos e as transformações dos códigos linguísticos são caminhos para a construção de um conhecimento autônomo e inovador. Não é uma habilidade intuitiva, e ainda dificultada em sistemas educacionais onde 0 apelo à memorização é preponderante no estudo e resolução de avaliações.

\section{Projeto SupyGirls : Proposta e Metodologia}

O SupyGirls é um projeto de extensão ofertado pela Universidade Federal do Rio de Janeiro visa promover e valorizar a ação feminina na área tecnológica. A equipe de extensionistas é composta por graduandas da UFRJ das áreas da saúde e educação. O 
VIII Congresso Brasileiro de Informática na Educação (CBIE 2019)

Anais do XXV Workshop de Informática na Escola (WIE 2019)

projeto ocorreu em uma escola pública municipal do estado do Rio de Janeiro, de agosto a julho de 2019, com uma aula semanal de 4 horas.

O processo contou com 28 participantes entre 12 e 16 anos, de ambos os sexos. A seleção baseou-se nos critérios: Baixo desempenho nas turmas regulares; Queixas de leitura e escrita e Multirrepetência. Respeitando o cronograma semestral da instituição traçou-se as seguintes competências-alvo do programa: funções executivas, Codificação e decodificação, Associação dos canais visual e motor, Níveis de Organização da informação e manipulação de representações concretas e abstratas.

\subsection{Analisando, Decompondo e recriando Games}

A primeira atividade ocorreu como um circuito de três jogos: a) Quem sou eu? ${ }^{1}$ consiste em um tabuleiro impresso com representações imagéticas da flora, fauna, ícones midiáticos e históricos, pontos turísticos e cartas correlatas aos signos indutores presentes no tabuleiro; b) ${ }^{2} \mathbf{A}$ academia da mente: $\mathbf{U m}$ a um composto de 26 cartas com figuras de conjuntos diversos (animais, automóveis, flores...) e números na face posterior, 2 cartas com símbolos de igualdade e diferença; c) Game MoonWalk ${ }^{3}$ composto de um tabuleiro quadrado, malhado $8 \times 8$ e 64 fichas de anterior e posterior branca e preta. A turma foi dividida em grupos proporcionais e direcionados ao mediador disponível. Nas três etapas do circuito a mediação teve por alvo o alinhamento lógico às seguintes etapas:

EXPERIMENTAÇÃO I: Duas ou três partidas eram jogadas de acordo com as regras do jogo. Durante a partida, o mediador propunha reflexões relativas às movimentações feitas em tabuleiro, utilizando-se da construção argumentativa dos estudantes na consciência de estratégias incoerentes e também otimização dos bons encadeamentos lógicos. Habilidades Computacionais Trabalhadas: Abstração, Paralelismo;

ANÁLISE E DECOMPOSIÇÃO: Após as partidas e compreensão das regras explícitas do jogo, segue-se para as camadas de abstração. Considerando a linguagem como um código hierárquico, disposto do nível concreto (sintaxe) ao mais abstrato(semântica) [Seminério, 1984], e o jogo como possível mediador entre a linguagem e o pensamento [Vigotsky, 1983], os estudantes foram direcionados através do discurso à concretização das regras e objetivos. Busca-se no exercício matemático, através das discussões, convergências com os princípios da álgebra booleana, por exemplo. Habilidades Computacionais Trabalhadas: Abstração, Coleta, Decomposição e Análise de dados, Simulação;

EXPERIMENTAÇÃO II: Posterior a estruturação do jogo em conceitos, inicia-se outra partida, os alunos fazem a mediação e julgamento sobre os movimentos produzidos. Habilidades Computacionais Trabalhadas: Abstração, Representação e Automação;

INOVAÇÃO: Nesta etapa os estudantes são desafiados a alterar, criar novas regras, objetivos e obstáculos para o jogo ou lidarem com modificações sugestionadas pelo mediador (Figura 4). Habilidades Computacionais Trabalhadas: Simulação, Representação;

\section{Resultados Parciais e Discussão}

A escolha pela abordagem desplugada fora propiciada pela indisponibilidade de recursos na instituição. A conexão de internet se mantém precária e os computadores não atendem a demanda de sala de aula. Quanto ao pensamento computacional, as habilidades balizadas como relevantes foram resultado da correspondência entre o planejamento curricular e as “Diretrizes para o ensino da computação” (SBC, 2017). O 
VIII Congresso Brasileiro de Informática na Educação (CBIE 2019)

Anais do XXV Workshop de Informática na Escola (WIE 2019)

pensamento computacional, contextualizado ao ensino fundamental pode ser visto na Tabela 1:

Tabela 1 - Correlação Pensamento Computacional e Exercício atrelado à competência

\begin{tabular}{|l|l|}
\hline $\begin{array}{l}\text { Abstração, } \\
\text { Representação } \\
\text { e Automação }\end{array}$ & $\begin{array}{l}\text { Organização lógica de objetos com base em atributos singulares } \\
\text { ou compartilhados (cor, tamanho, forma, texturas, detalhes...), } \\
\text { pensamento algorítmico, compreensão e manipulação autônoma } \\
\text { das informações }\end{array}$ \\
\hline $\begin{array}{l}\text { Coleta, } \\
\text { Decomposição } \\
\text { e Análise de } \\
\text { Dados }\end{array}$ & $\begin{array}{l}\text { Identificação de padrões, projeção de sistemas, relação entre } \\
\text { dados, inferências, ilustração de estruturas nos mais diversos } \\
\text { templates (lista, quadro de x entradas, grafos, árvores...) }\end{array}$ \\
\hline Paralelismo & Identificação de atividades executáveis em concomitância \\
\hline Simulação & Definição ou simulação de experimentos \\
\hline
\end{tabular}

Quanto a execução das atividades, pontua-se o envolvimento dos alunos e suas principais dificuldades nas propostas: Gradualmente os alunos demonstraram maior facilidade de argumentação, composição lógica e resolução de problemas frente aos novos desafios. Estes passaram a manifestar adaptações de esquemas de solução anteriores às novas propostas. $\mathrm{O}$ avanço da receptividade e entrosamento alunomediador também pôde ser observada, até mesmo nos alunos que aparentavam ser mais dispersos. Observou-se também que tarefas que demandam maior nível de abstração, passaram a ter intermediação dos próprios alunos.
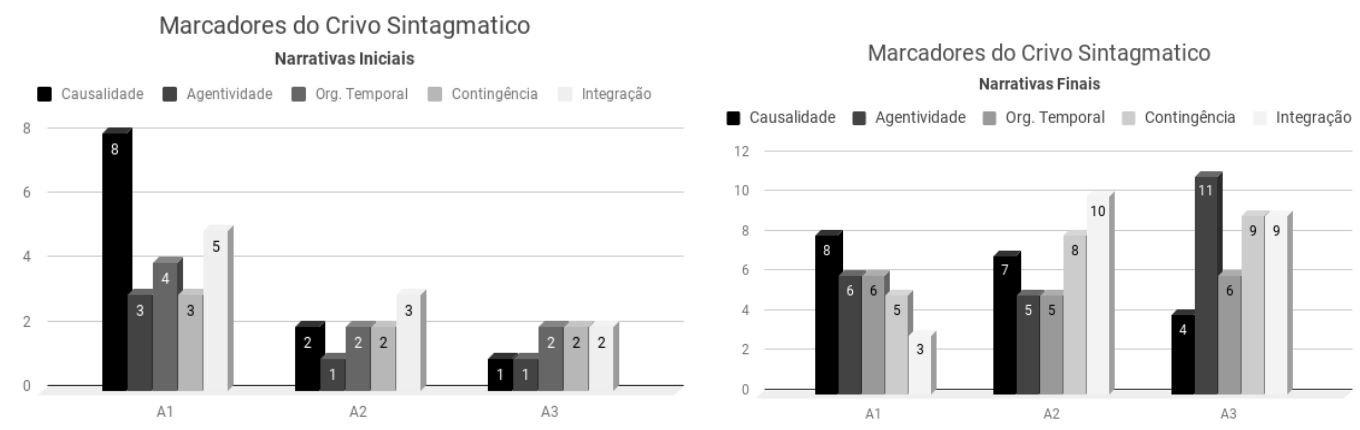

\section{Gráficos 1 e 2. Média de ocorrência de Marcadores Textuais das narrativas iniciais e finais, respectivamente.}

Os gráficos 1 e 2 manifestam o desenvolvimento textual através de comparações de narrativas iniciais e finais de três alunos. No eixo vertical consta a média mínima e máxima do aparecimento de cláusulas textuais de cada texto, e no eixo horizontal, em barras, o posicionamento dos Alunos A1, A2 e A3 na média. Para a análise, considerou-se aspectos macroestruturais descritos no crivo sintagmático de [Seminério, 1998]: Causalidade, Agentividade, Organização Temporal, Contingência e Integração.

Os dados denotam melhoras significativas no corpo textual dos alunos. Destacase o aumento na utilização de elementos de integração/coesão textual, contingência (entrelaçamento de acontecimentos), organização temporal e agentividade. Tais marcadores são essenciais na comunicação e apontam preocupação com a 
VIII Congresso Brasileiro de Informática na Educação (CBIE 2019)

Anais do XXV Workshop de Informática na Escola (WIE 2019)

linearidade textual, fluência e intenção dialética uma vez que a principal motivação para a escrita compartilhada é o entendimento do potencial leitor.

\section{Considerações Finais}

O vigente trabalho é um recorte da atuação em instituições educacionais de áreas conflagradas e pouco acolhidas em recursos materiais. Tem por finalidade a exposição de metodologias benéficas aos alunos com histórico de problemas de aprendizagem não alcançados pelas políticas públicas de saúde. Como trabalhos futuros, objetiva-se proceder com o atual com o uso a utilização de computadores e introdução à linguagem de programação. Publicação da análise detalhada dos resultados em um artigo posterior.

\section{Referências}

GUARDA, Graziela; GOULART, Ione. Jogos Lúdicos sob a ótica do Pensamento Computacional: Experiências do Projeto Logicamente. Brazilian Symposium on Computers in Education (Simpósio Brasileiro de Informática na Educação - SBIE), [S.l.], p. 486, out. 2018. ISSN 2316-6533.

Instituto Nacional de Estudos e Pesquisas Educacionais Anísio Teixeira /INEP/ (2018). "Índice de desenvolvimento da educação brasileira $-4^{\circ}$ e $5^{\circ}$ série". http://ideb.inep.gov.br/resultado/resultado/resultado.seam?cid=2671975, Julho

(2018). "Índice de desenvolvimento da educação brasileira - $8^{\circ}$ e $9^{\circ}$ série". http://ideb.inep.gov.br/resultado/resultado/resultado.seam?cid=2739371, Julho

Jogo Quem sou eu? Master. São Paulo: Toia. 1 jogo (Papel cartão, tabuleiro);

Jogo Um a Um Academia da Mente. São Paulo: Estrela. 1 jogo ( 25 fichas, 26 cartas com figuras e números, 2 cartas com símbolos, 1 ampulheta );

Jogo MoonWalk. São Paulo: Mind Lab: Artigos Recreativos. 1 jogo (1 tabuleiro 64 peças "dupla face" - 1 pino claro - 1 pino escuro);

Marques, C. V. M. EICA - Estruturas Internas Cognitivas Aprendentes: Um Modelo Neuro-Computacional aplicado à instância psíquica do Sistema Pessoa em Espaços Dimensionais. Tese de Doutorado. Rio de Janeiro: COPPE/ UFRJ, 2017.

Ruedaa, M. R, PhD, Paz-Alonso, P. M.PhDb (2013), "Função Executiva e Desenvolvimento Emocional" , Universidad de Granada, Espanha, Basque Center on Cognition, Brain and Language.

Seminério, F. L. P.; Araújo, T. C. F.; Oliveira, R. M.; Raimundo, C.; Mourão, B. L. A.; Botelho, M. G. B. e Cerqueira, L. C. (1998). "Metaprocesso: A chave do desenvolvimento cognitivo. uma reavaliação da pedagogia contemporânea”. Fundação Getúlio Vargas, Rio de Janeiro, RJ.

SEMINÉRIO, F. L. P, (1984). "Infra-Estrutura da Cognição: Fatores Ou Linguagens”. Fundação Getúlio Vargas - RJ

Shimamura A. e J. Metcalfe (1992). "Metacognition: Knowing about Knowing”. Massachusett Institute of Technology, Cambrige, MA.

Sociedade Brasileira de Computação, (2017) "Diretrizes para ensino de Computação na Educação Básica", https://www.sbc.org.br/documentos-da-sbc/summary/131-curriculos-dereferencia/1177-diretrizes-para-ensino-de-computacao-na-educacao-basica, Julho.

Sociedade Brasileira de computação (2018), “Itinerário Formativo da Computação”http:// www.sbc.org.br/documentos-da-sbc/summary/203-educacao-basica/1216-itinerarioinformativo-da-computacao, Julho.

Vigotsky, L. S. (2005). “Pensamento $\boldsymbol{e}$ linguagem." São Paulo: Martins Fontes (194 páginas) ( $1^{\mathrm{a} e d .}$ 1987).

Wing, J. M. (2006). “Computational thinking”. Communications, ACM, Vol. 49, No. 3. 33-35. 